\title{
PRIMER REGISTRO DE LEDENBERGIA MACRANTHA STANDLEY (PHYTOLACCACEAE) EN EL ESTADO DE VERACRUZ, MEXICO
}

\author{
Hector Oliva Rivera y feliza Ramon farias \\ Facultad de Biología de la Universidad Veracruzana \\ Apartado Postal 177 \\ Córdoba, Veracruz, México
}

\section{RESUMEN}

Se registra por primera vez para la flora del estado de Veracruz Ledenbergia macrantha Standley (Phytolaccaceae), en el municipio de Amatlán de los Reyes, y se incluyen datos sobre su distribución conocida en el pais.

\begin{abstract}
Ledenbergia macrantha Standley (Phytolaccaceae) is reported for the first time for the flora of the state of Veracruz, in the municipality of Amatlan de los Reyes; some additional data on its distribution in the country are included.

Esta especie se colectó en el mes de marzo de 1990, en el municipio de Amatlán de los Reyes y constituye la primera vez que se conoce para el estado de Veracruz. La búsqueda de datos bibliográficos que nos permitiera conocer su distribución geográfica en el continente americano, indicó su presencia en algunos paises de América Central, particularmente en Guatemala (Standley y Steyermark, 1946), El Salvador (Standley y Calderón, 1927), asi como en Nicaragua (Seymour, 1980).

Para la República Mexicana, Rzedowski (1965) consigna esta especie en las localidades de Atenquique, Jalisco y en Coalcomán, Michoacán, este último lugar tomando en cuenta el ejemplar Hinton 13641, depositado en el herbario US en los Estados Unidos.

La revisión de los herbarios ENCB, IBUG, MEXU y XAL, permitió actualizar su distribución conocida en México, encontrándose colectada sólo en algunos estados de la vertiente del Océano Pacífico, de manera que este primer hallazgo para el este de México, amplía su área a una zona alejada unos $1000 \mathrm{~km}$ de los registros previos antes mencionados (Fig. 1).

A continuación, se incluye una corta descripción de la especie, tomando en cuenta las plantas colectadas en el estado de Veracruz.

Ledenbergia macrantha Standley, Journ. Wash. Acad. Sci. 13: 350. 1923.

Flueckigera macrantha P. Wilson, North Amer. Flora 21: 260. 1932.

Arbol femenino de 6-8 $\mathrm{m}$ de altura. Ramas horizontales algo péndulas, ramillas glabras. Hojas simples, glabras, agrupadas en las partes terminales de las ramillas, lámina
\end{abstract}




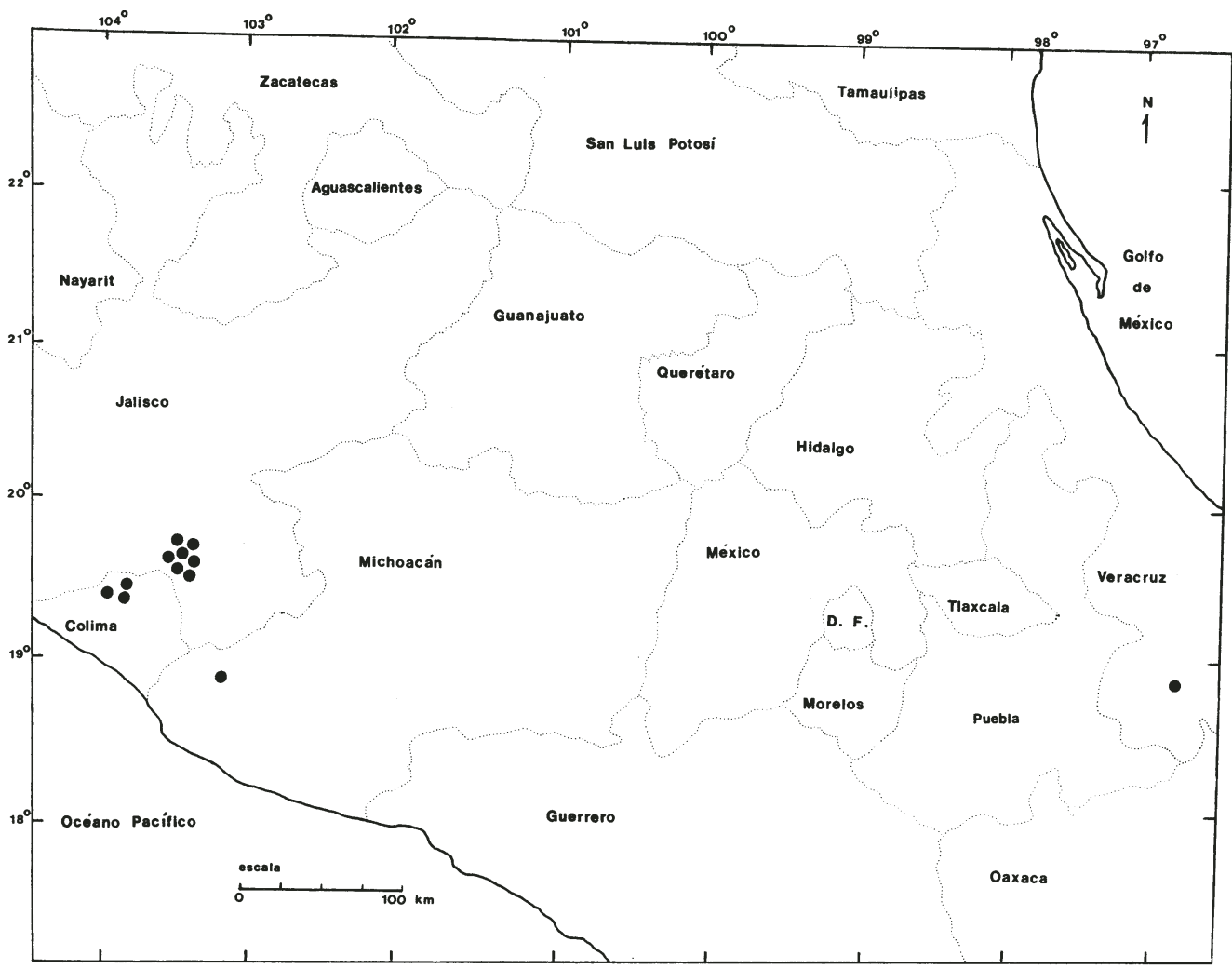

Fig. 1. Mapa de la distribución conocida de L. macrantha Standley en la República Mexicana (๑).

lanceolado-elíptica y algunas veces con forma ovada, verde obscura en el haz y clara en el envés; de 4-13 cm de largo y de $2-7 \mathrm{~cm}$ de ancho, nervadura central marcada en el haz y por lo menos 6 pares de nervaduras secundarias definidas, base redondeada a ligeramente aguda, a veces asimétrica, borde entero, a veces ligeramente crenulado u ondulado, ápice agudo o a veces acuminado, peciolo de $1-8 \mathrm{~cm}$ de longitud, delgado, generalmente glabro y rojizo, velutino en la unión con la lámina. Inflorescencias en racimos péndulos, con una longitud hasta de $16 \mathrm{~cm}$, raquis delgado de $1 \mathrm{~mm}$ de diámetro. Flores distribuidas en forma alterna en el raquis, pedicelos verdosos de 5-7 $\mathrm{mm}$ de largo, perianto de 4 piezas verdosas o amarillentas, cada una de ellas de forma espatulada de $8-11 \mathrm{~mm}$ de largo y 3-4 mm en su parte más ancha, superficie reticulada, algo brillantes y persistentes en el fruto. Fruto un aquenio, de forma globosa con la superficie reticuladorugosa, de color amarillento paja, de $3 \mathrm{~mm}$ de longitud y $4 \mathrm{~mm}$ de diámetro y con una costilla longitudinal. Semilla, una por fruto, de forma lenticular, de $3 \mathrm{~mm}$ de largo, testa negra, lustrosa, con la superficie de aspecto granuloso, endospermo blanquecino, embrión curvo. 
Hábitat: Arbol escaso en cafetal, con relictos de una selva mediana subperennifolia, donde, entre otros, se encuentran los géneros siguientes: Plumeria, Bursera, Bernoullia, Pseudobombax, Chamaedorea, Wimmeria; suelo somero con abundante materia orgánica y rocas calizas aflorantes.

Material examinado: México, Veracruz, municipio de Amatlán de los Reyes, Cerro de la cueva de Lourdes, $700 \mathrm{~m}$ s.n.m., 22 de marzo de 1990, H. Oliva, F. Ramón y C. Huerta, HOR-677 (ejemplar femenino con frutos y hojas tiernas); ibid. H. Oliva y F. Ramón, HOR701 (ejemplar con pocos frutos y hojas maduras). Los especímenes de respaldo están depositados en los herbarios XAL, MEXU y en la Unidad Docente Interdisciplinaria de Ciencias Biologicas y Agropecuarias en Peñuela, Veracruz.

\section{AGRADECIMIENTOS}

Los autores agradecen la colaboración del M.C. Miguel de J. Cházaro B., de la Universidad de Guadalajara, de la Biól. María de los Angeles Guadarrama O., del Herbario de la Universidad Juárez Autónoma de Tabasco (UJAT), y del M.C. Mario Vázquez T., del Centro de Investigaciones Biológicas de la Universidad Veracruzana, a todos ellos por la revisión general del manuscrito. A las autoridades de los herbarios XAL, MEXU y ENCB, se dan gracias por las facilidades prestadas para la consulta de sus colecciones y al Biól. Jesús Guerrero N., por su gran ayuda en la revisión de las tarjetas de herbario de los ejemplares depositados en IBUG.

\section{LITERATURA CITADA}

Rzedowski, J. 1965. Algunas fanerógamas nuevas para la flora de México, con notas relativas al género Ledenbergia (Phytolaccaceae). An. Esc. Nac. Cienc. Biol. Méx. 14: 25-34.

Seymour, F. C. 1980. A check list of the vascular plants of Nicaragua. Phytologia Memoirs. 1: 275.

Standley, P. C. y S. Calderón. 1927. Listado preliminar de las plantas de El Salvador. Imprenta Nacional. San Salvador, El Salvador. p. 385.

Standley, P. C y J. A. Steyermark. 1946. Flora of Guatemala. Fieldiana Botany 24(4): 194-195. 